\title{
Static and Fatigue Failure of Adhesively Bonded Laminate Joints in Moist Environments
}

\author{
KATNAM K. B., ${ }^{1}$ CROCOMBE A. D., SUGIMAN AND KHORAMISHAD H. \\ Mechanical, Medical and Aerospace Engineering (MMA), Faculty of Engineering and \\ Physical Sciences, University of Surrey, Guildford, Surrey, UK, GU2 7XH
}

\section{ASHCROFT I. A.}

Wolfson School of Mechanical and Manufacturing Engineering, Loughborough University, Leicestershire, UK, LE11 3TU

\begin{abstract}
Advanced structural adhesives are now an important joining technique in automobile and aerospace applications. The perceived uncertainty in the long-term structural performance of bonded members when subjected to static/fatigue loads in aggressive environments is probably restricting an even more widespread use of this joining technology. In this paper, the effect of moisture on the static and fatigue resistance of adhesively bonded laminate joints was investigated. Experimental tests were performed on both aged and unaged adhesively bonded laminate joints for static and fatigue responses. Further, using a cohesivezone approach for the adhesive bondlines, a combined diffusion-stress analysis was developed to predict the progressive damage observed in the joints tested experimentally. The numerical predictions were found to be in good agreement with the experimental test results.
\end{abstract}

KEYWORDS: Adhesively bonded laminates, moisture effect, static failure, fatigue failure, cohesive-zone modelling, coupled diffusion-stress analysis, 2024-T3 aluminium and FM73 adhesive.

\section{INTRODUCTION}

With advances in polymer science, high-performance structural adhesives have become a common constituent in the aerospace, automotive, and construction sectors in recent times. Advanced structural adhesives are often employed: (a) to join primary and/or secondary structural members and (b) in manufacturing of advanced composite materials such as Glare. Though structural adhesive bonding has several advantages over conventional joining

\footnotetext{
${ }^{1}$ Corresponding author: a.crocombe@surrev.ac.uk. Tel: +44 1483689194
} 
1 techniques such as riveting and bolting, understanding and quantifying the long-term durability of adhesively bonded joints under service conditions is a key area of interest and has received a lot of research attention in recent times.

Adhesively bonded joints are often subjected to aggressive environments together with static/fatigue loading conditions. The combined effect of these service conditions in combination may be more damaging than the adverse effect of each individual condition. An aggressive environment can adversely influence the bond strength and degrade the structural performance of adhesively bonded joints when exposed over long periods (Kinloch, 1983; Kinloch, 1995; Rodriguez, 1996). Moisture is a commonly encountered aggressive environment in many structural applications. Water molecules diffuse into adhesively bonded joints and can degrade both adherend-adhesive interface and adhesive (Minford, 1985; Devis and Watts, 1996; Sargent, 2005; Gerald Doyle and Richard Pethrick, 2009; Brewis et al., 1990; de Nèvea and Shanahan, 1992). This invariably influences the joint strength (Bowditch, 1996; Armstrong, 1997; Loh et al., 2005). This is shown schematically in Figure 1.

Moisture attacks the bulk adhesive through reversible, e.g. plasticization and swelling, and irreversible, e.g. hydrolysis and micro-crack formation. An epoxy adhesive is susceptible to moisture attack because it has hydrophilic groups that attract water molecules (Rider et al., 2004). The hydroxyl (-OH) groups in epoxy adhesives can form hydrogen bonds with water molecules. Absorption of water molecules between the molecular chains of polymer results in degradation of mechanical properties based on the moisture concentration. Plasticization induces plastic deformation and lowers the glass transition temperature $(\mathrm{Tg})$, whereas swelling is related to the differential strain that is created by the expansion force exerted by moisture while stretching polymeric chains (Adams and Comyn, 1997). The effect of water, at least initially, can be reversible. This is especially true when corrosion-resistant adherends, good surface preparation and treatment, and hydrolytically stable adhesives are involved. 
1 The bond (interface) strength depends on the quality of the adherend surfaces being bonded 2 together (Wolfe et al., 1997; Ingram and Ramani, 1997; Rider and Arnott, 1996; Turner et al., 3 1997). When exposed to moist environments for long periods, the diffusion of water molecules will cause an unstable adhesive-adherend interface. Moisture attack often occurs in the interfacial regions of the bonded joints with metal adherends. Some of the mechanisms of adherend-adhesive interface failure are: (a) weakening/breaking of secondary bonds at the interface, (b) failure of the oxide layer on the metallic adherend through hydration or corrosion and (c) hydrolysis of the adhesive boundary layer (Adams and Comyn, 1997). The adherend surfaces are often treated with etching and anodising processes to improve the strength and the durability of adhesively bonded joints. Primers provide corrosion resistance to adherend surfaces in moist environments. Two-phase epoxy adhesives, e.g. rubber toughened adhesives, are often used to improve adhesive fracture properties. The water molecules may attack particle-adhesive interface and influence the micro-failure mechanisms that govern crack growth and mode of failure (Takafumi and Raymond, 2004).

In many situations, the moisture diffusion process is accompanied by fatigue loading conditions. The combined moisture-fatigue conditions often accelerate the damage accumulation in adhesively bonded joints (Fernando et al., 1996; Abdel Wahab et al., 2001; Dikie et al., 1998; Ning Sua et al., 1992). On the one hand, the moisture uptake can accelerate the fatigue damage accumulation, and, on the other hand, the fatigue damage of the adhesive can accelerate the moisture diffusion process. In this regard, it is necessary to conduct carefully designed experiments on adhesively bonded joints that are subjected to moist environments and fatigue loading to investigate the combined moisture-fatigue joint response. Further, developing numerical models to accurately predict the experimentally observed failure behaviour is vital from a design viewpoint.

Cohesive zone models are being increasingly used in finite element analysis to model the failure behaviour of adhesively bonded joints (Liljedahl et al., 2006). A cohesive-zone approach is particularly useful when both damage initiation and propagation phases in the adhesive bondline need to be incorporated in finite element analysis. Generally, a tractionseparation response is assumed to model the damage initiation and evolution in the fracture 
1 process zone (Barrenblatt, 1962; Dugdale, 1960), and a parameterized traction-separation

shape is generally employed in the analysis (Alfano, 2006). The parameters that define the traction-separation response mainly are the cohesive fracture energy and the cohesive strength of the adhesive in each fracture mode (Diehl, 2008). Combined experimentalnumerical approaches are commonly used to determine the cohesive parameters. Once the cohesive parameters for each fracture mode are determined, the model can make accurate predictions for the entire fracture process of any joint geometry and under any applied loads.

In this paper, the moisture effect on the static and fatigue behaviour of adhesively bonded laminate joints is investigated using experimental and numerical approaches. The adhesive system used in the study was Al2024-T3 aluminium and FM73 toughened-epoxy adhesive. The adhesively bonded laminate joints were exposed to de-ionised water at $50^{\circ} \mathrm{C}$. Aged and unaged joints were tested to examine the effect of moisture on both static and fatigue responses. Using cohesive-zone modelling, a combined diffusion-stress analysis was developed to predict static and fatigue behaviour of the aged joints. The methodology developed and the results obtained are presented.

\section{EXPERIMENTAL WORK}

\subsection{Materials and Joints}

Adhesively bonded laminate joints were used to experimentally investigate the effect of moisture on their static and fatigue failure behaviour. Experimental tests were conducted on three joint configurations: (a) doublers in three-point bending (DB), (b) full-width single lap joints (FSLJ), and (c) reduced-width single lap joints (RSLJ). The joints were cut from the bottom skin of a potential wing panel (laminate skin and bonded stringer combination) that was manufactured using Al 2024-T3 and a rubber-toughened epoxy adhesive FM73 (Katnam et al., 2009). The laminate was manufactured using aluminium laminae and adhesive FM73. The stringer (monolithic Al 2024-T3) was bonded to the laminate using adhesive FM73. The thickness of each aluminium lamina and adhesive bondline in the laminate were $1.3 \mathrm{~mm}$ and $0.1 \mathrm{~mm}$, respectively. The monolithic aluminium substrate was $9.65 \mathrm{~mm}$ thick. The adhesive bondline between the stringer and the laminate was between $0.2-0.1 \mathrm{~mm}$ thick because of the 
1 initial curvature of the laminate. All the bonded aluminium surfaces were pre-treated with a

2 Chromic Acid Etch (CAE) followed by a Phosphoric Acid Anodise (PAA), and BR127

3 primer was used for better corrosion resistance. The geometry and dimensional details of the

4 joints are shown in Figure 2. The DB joint was tested under three-point bending, and the

$5 \quad$ FSLJ and RSLJ were tested under tensile load.

\section{$7 \quad 2.2$ Ageing Conditions}

8 In order to investigate the effect of moisture on static and fatigue response, the joints were 9 exposed to laboratory ageing conditions. The joints were immersed in de-ionised water at a constant temperature of $50^{\circ} \mathrm{C}$ to accelerate the ageing process.

\subsection{Static Tests on Aged and Unaged Joints}

Static tests were conducted on unaged and aged (at different withdrawal times) joints to experimentally determine the effect of moisture on the static strengths. The DB joints were tested under three-point bending at $0.5 \mathrm{~mm} / \mathrm{min}$ rate for unaged and aged (after 360 days) conditions. The FSLJ and RSLJ joints were tested under tensile load at $0.1 \mathrm{~mm} / \mathrm{min}$ rate for unaged and aged (after 360 and 720 days) conditions. The static failure loads so obtained are given in Section 4.1.

\subsection{Fatigue Tests on Aged and Unaged Joints}

21 Similarly, the effect of moisture on the fatigue response was experimentally investigated. 22 Fatigue tests were conducted on unaged and aged (at different withdrawal times) joints and 23 load-life curves were obtained. All the fatigue tests were conducted at room temperature 24 under a sinusoidal load controlled condition. The load ratio (R) was 0.1 and the frequency (f) was $5 \mathrm{~Hz}$. The DB joints were tested under three-point bending for unaged and aged (after 360 days) conditions at different load levels. The FSLJ and RSLJ joints were tested under tensile load for unaged and aged (after 360 and 720 days) conditions at different load levels. The moisture-dependent load-life curves so obtained are given in Section 4.2. 
2 To predict the adverse effect of moisture on the static and fatigue failure behaviour of 3 adhesively bonded laminate joints, a numerical strategy was developed using the finite 4 element method. Crocombe (Crocombe, 1997) and Hua et al. (Hue et al., 2008) proposed a 5 coupled mechanical-diffusion analysis strategy for predicting static failure loads of 6 environmentally degraded adhesively bonded joints. A similar approach was adopted in this 7 work to predict the moisture effect on both static and fatigue behaviour of adhesively bonded 8 joints when exposed to moist environments. A cohesive-zone approach was used to model the 9 failure of adhesive bondlines. The numerical models were implemented using 10 Abaqus/Standard version 6.9. The assumptions made in the numerical models are: (a) A bi11 linear traction-separation response represents the adhesive bondline damage/failure (Yang, 12 2001), (b) a moisture-dependent traction-separation response represents the moisture degradation of the bond line (Liljedahl, 2006), (c) the fatigue damage of the adhesive bondline degrades the bi-linear traction-separation response, (c) the damage due to moisture and the damage due to applied stresses are cumulative, (d) the moisture diffusivity of the adhesive material remains constant (does not depend on the moisture concentration), and (e) the moisture uptake in the adhesive material follows the Fickian diffusion law (Liljedahl, 2006).

\subsection{Moisture Diffusion Analysis}

The moisture distributions in adhesive bondlines were predicted using a heat-transfer analysis (used to model an analogous moisture-diffusion analysis) for the DB, FSLJ and RSLJ specimens that were immersed in de-ionised water. The governing partial differential equations for heat-transfer and moisture-diffusion are given in Equations (1) and (2) - where $\theta, \mathrm{c}, \mathrm{K}, \mathrm{D}$ and $\mathrm{t}$ are temperature, moisture concentration, thermal diffusivity, moisture diffusivity and time, respectively. 
1 By setting both the specific heat and the density of the adhesive bondline to 1 , the thermal 2 diffusivity analysis can be used to model the moisture diffusion in the adhesive material. The nodal temperatures obtained will represent the nodal moisture concentrations. In this work,

4 the moisture concentrations in adhesive bondlines were normalised ( 0 to 1$)$ for dry and 5 saturated adhesive conditions respectively. The moisture concentration on the adhesive 6 boundary that was in contact with the de-ionised water, was set to 1 thus assuming immediate 7 saturation it the boundary (a common assumption in Fickian models). In order to model the moisture diffusion in the joints, the aluminium-adhesive interface was assumed as insulated (using a unit value for the density and very small values for the diffusivity and the specific heat).

\subsection{Cohesive Zone Modelling}

13 The current static and fatigue damage models were developed using the cohesive zone approach for the adhesive FM73. The adhesive bondline between the bonded stringer and the laminate in the DB, FSLJ and RSLJ was experimentally found to control the failure behaviour and the inter-laminar adhesive bondlines were observed to be free from static and fatigue damage. For this reason, three-dimensional cohesive zone elements (COH3D) with a bi-linear traction-separation response were used to model the adhesive between the stringer and the laminate, whereas the inter-laminar bondlines, the aluminium laminae and the stringer were modelled using damage-free continuum elements (C3D8). In adhesively bonded joints, the cohesive zone model assumes that cracks nucleate in a small fracture process zone, typically due to crazing and shear yielding of the adhesive. In this process zone, adhesive stress (traction) initially increases with separation and starts to decrease after reaching a maximum value (tripping traction). The adhesive stresses become zero when the separation reaches a certain value (failure separation). A bi-linear traction-separation response is assumed in the current model. Further, by defining traction-separation responses for peel and shear, a mixed-mode analysis was performed. 


\section{$1 \quad$ 3.3 Static Analysis}

2 The effect of moisture on the static failure load of DB, FSLJ and RSLJ was modelled using a coupled stress-diffusion analysis as show in Figure 3a. For any given exposure time, a "moisture-diffusion" analysis was performed to calculate the moisture concentrations (nodal temperatures) in the adhesive bondline between the stringer and the laminate. In Abaqus/Standard 6.9 the nodal output NT11 obtained from the heat-transfer analysis was exported into the stress analysis. The cohesive properties used for the unaged condition were assumed to degrade linearly with moisture concentrations.

$$
\sigma_{m}=\sigma_{m}^{d}(1-c)+c \sigma_{m}^{s}
$$

$$
\Gamma_{m}=\Gamma_{m}^{d}(1-c)+c \Gamma_{m}^{s}
$$

$$
E=E^{d}(1-c)+c E^{s}
$$

By defining the tripping tractions and fracture energies as moisture-dependent, the tractionseparation response of the cohesive zone (adhesive bondline between the stringer and the laminate) was varied as given in Eq. (3) and the effect of moisture on the static failure load was modelled. In Eq. (3), $\left(\sigma_{m}^{d}, \Gamma_{m}^{d}, E^{d}\right)$ and $\left(\sigma_{m}^{s}, \Gamma_{m}^{s}, E^{s}\right)$ are the tripping traction, the fracture energy and the Young's modulus for unaged and aged conditions respectively, and $\mathrm{c}$ is the moisture concentration.

\subsection{Fatigue Analysis}

Similarly, the moisture effect on the fatigue failure of DB, FSLJ and RSLJ was modelled using a coupled stress-diffusion analysis as shown in Figure 3b. Initially, a "moisturediffusion" analysis was performed to calculate the moisture concentrations (nodal temperatures) in the adhesive bondline between the stringer and the laminate for any given exposure time and the nodal output NT11 obtained from the heat-transfer analysis was exported into the stress analysis. As with the static analysis, the traction-separation response of the cohesive zone was degraded with the calculated moisture concentrations. However, the 
1 2009) was used to model the fatigue damage based on the moisture-dependent tractionseparation response.

4 In the strain-based fatigue damage model, a fatigue damage parameter is a function of the 5 principal maximum strains in the adhesive bondline. The fatigue damage equation is given in 6 Eq. (4) - where $\mathrm{D}$ is the damage variable, $\mathrm{N}$ is the number of fatigue cycles, $\varepsilon_{\mathrm{p}}$ is the maximum principal strain in the adhesive bondline (the cohesive zone), $\varepsilon_{\mathrm{t}}$ is the threshold strain (represents fatigue endurance), and $\alpha, \beta$ are the adhesive system constants. The cohesive properties that are degraded based on the moisture concentrations in Eq. (3) are further degraded using the fatigue damage variable as in Eq. (5).

$$
\hat{\Gamma}_{m}=\Gamma_{m}(1-D)
$$

The degradation of the mixed-mode traction-separation response for moisture ageing and fatigue cycles is schematically illustrated in Figure 4a, where the mode-I, mode-II fracture energies and the phase angle (mode-mixity) are $\Gamma_{\mid}, \Gamma_{\|}$and $\phi$, respectively. Initially, the mixed-mode traction-separation response was degraded for moisture uptake by decreasing the tripping traction, the initial stiffness (Young's modulus) and the fracture energy assuming a constant failure separation. However, during the fatigue degradation the tripping traction and the fracture energy were decreased leaving the initial stiffness and the failure separation as constant (see Figure 4b).

The fatigue degradation is an iterative procedure and is done by dividing the total fatigue life into several blocks of fatigue cycles. The static response of the joint under maximum fatigue load $\left(\mathrm{P}_{\max }\right)$ is used to calculate the maximum principal strains in the cohesive zone elements and the fatigue damage variable $\mathrm{D}$ is evaluated at the end of each block of fatigue cycles. 
1 load. The details of this iterative procedure can be found in Khoramishad et al. (Khoramishad 2 et al., 2009).

\section{DETAILS AND RESULTS}

5

6

A non-linear material model with strain-hardening was used to model Al 2024-T3 and all the adhesive bondlines in the laminate were modelled using a linear-elastic material response. However, the adhesive bondline between the stringer and the laminate was modelled as a cohesive zone with a bi-linear traction-separation response. The material properties used in the modelling are given in Table 1. Tensile tests were conducted on Al 2024-T3 and the yield stress, the ultimate stresses and the elongation were obtained experimentally.

To model the adhesive bondline between the stringer and the laminate, the cohesive zone properties were tuned using an experimental-numerical approach (Katnam et al., 2009). In this work, initially, both unaged and aged (saturated) laminate specimens were tested using a miniature (thin laminate slices of $1 \mathrm{~mm}$ width) cantilever peel test setup and the load-crack curves were measured. Later, using a cohesive zone modelling, the load-crack curves were 
1 predicted by adjusting the cohesive properties for both unaged and saturated adhesive conditions. The cohesive properties obtained for FM73 are given in Table. 2.

4 The finite element mesh used to model the DB and the RSLJ (similar to the FSLJ) are shown 5 in Figure 6 . The adhesive bondline between the stringer and the laminate, modelled with the 6 cohesive elements (COH3D) for both the static and the fatigue analysis can also be seen in

7 Figure 6. The sweep-mesh and the structured-mesh techniques available in Abaqus/Standard 86.9 were used for the cohesive zone and the rest of the model (with C3D8 elements), 9 respectively. The typical size of a cohesive element was $0.2 \mathrm{~mm} \times 0.5 \mathrm{~mm} \times 0.5 \mathrm{~mm}$. The BK law (Benzeggagh and Kenane, 1996) available in Abaqus/Standard 6.9 for a mixed-mode analysis was used for the damage evolution.

\subsection{Moisture Diffusion}

Moisture concentrations were calculated for different exposure times for the DB, FSLJ and RSLJ configurations using a "moisture-diffusion" analysis. The focus was on the adhesive bondline between the stringer and the laminate though the complete joint configuration was considered in the analysis. The total step time in the "diffusion" analysis was 720 days for the DB, FSLJ and RSLJ models. The boundary normalised concentration was assumed as 1 and through a transient analysis the normalised moisture concentrations (nodal temperatures) were calculated for two different exposure times (360 days and 720 days). The diffusivity used in the analyses was $0.0451 \mathrm{~mm} /$ day (Liljedahl, 2006). The estimated normalised moisture concentrations are shown in Figure 7. Only the adhesive bondline between the stringer and the laminate was shown with the constant moisture boundaries shown as dashed lines. From Figures $7 \mathrm{a}$ and $7 \mathrm{~b}$, it can be seen that the adhesive bondline was unsaturated in the DB and FSLJ specimens though both were exposed for 720 days. However, in the RSLJ the adhesive bondline was nearly saturated after 360 days of exposure. These estimated moisture concentrations were exported into the static and fatigue failure phase to degrade the cohesive properties. 
1 Static failure tests were conducted on the unaged and the aged DB, the FSLJ and the RSLJ.

2 Two different exposure times (360 and 720 days) were considered for the aged static tests.

3 The static failure surfaces obtained from the unaged and the aged joints revealed a cohesive

4 failure pattern. The static failure surfaces obtained from the DB tests are shown in Figure 8.

5 Only a part of the failure surfaces was shown (see Figure 8a). The unaged and the aged static

6 failure surfaces, seen in Figures $8 \mathrm{~b}$ and 8c, show the cohesive failure with some near-

7 interfacial patches. Further, the static failure surfaces obtained from the RSLJ tests are shown

8 in Figure 9. Similar to the failure surfaces obtained from the DB tests, the unaged and the

9 aged static failure surfaces, given in Figures $9 \mathrm{~b}$ and 9c, also show the cohesive failure with some near-interfacial patches. The crack initiated near the fillet region for the DB as the bending moment applied is high at that section. However, in the case of the RSLJ (and the FSLJ), the crack initiated from the tip of the artificial groove (this groove was made to convert a doubler into a single lap joint).

Using the coupled stress-diffusion model, the static failure loads were obtained for the DB, the FSLJ and the RSLJ configurations. The predicted results were compared against the experimental test data and they are shown in Figure 10. For the DB, both unaged and aged (360 days exposure) conditions were shown. The average static failure obtained for the unaged DB, FSLJ and RSLJ from experiments - $5.89 \mathrm{kN}( \pm 0.24 \mathrm{kN}), 10.76 \mathrm{kN}( \pm 0.22 \mathrm{kN})$ and $3.62 \mathrm{kN}( \pm 0.27 \mathrm{kN})$, respectively - were in good correlation with the predicted unaged static strengths - $5.72 \mathrm{kN}, 10.52 \mathrm{kN}$ and $3.60 \mathrm{kN}$, respectively. Similarly, the numerical models were in good agreement with the aged test data (after 360 and 720 days). A reduction in static failure load was seen in all the joints after the period of exposure.

\subsection{Fatigue Failure Tests and Analysis}

Fatigue failure tests were performed on the unaged and the aged DB, the FSLJ and the RSLJ at different load levels to obtain load-life curves. Two different exposure times (360 and 720 days) were considered for the aged fatigue tests. As with the static failure, the fatigue failure surfaces of the unaged and the aged joints also showed a cohesive failure pattern. The fatigue failure surfaces of the DB joints are shown in Figure 11. Only a part of the failure surfaces 
1 was shown (see Figure 11a). The unaged and the aged fatigue failure surfaces, seen in 2 Figures $11 \mathrm{~b}$ and $11 \mathrm{c}$, show a cohesive failure with some near-interfacial patches. Further, the 3 fatigue failure surfaces obtained from the RSLJ tests are shown in Figure 12. The unaged and the aged fatigue failure surfaces, seen in Figures $12 \mathrm{~b}$ and 12c, also show cohesive failure with some near-interfacial patches. The crack initiated near the fillet region for the DB and in the case of the RSLJ (and the FSLJ) the crack initiated from the tip of the artificial groove.

8 The strain-based fatigue damage model along with the coupled stress-diffusion analysis was used to predict the fatigue failure of the unaged and aged joints. The user-subroutine *USDFLD available in Abaqus/Standard 6.9 was used to implement a solution-dependent material response for the cohesive zone. The static response of the joints under the fatigue maximum load $\left(\mathrm{P}_{\max }\right)$ was used to initially calculate the fatigue damage variable (D). The iterative procedure was performed by dividing the total step time (fatigue life) into a number of increments (blocks of cycles). The details of this procedure can be found in Khoramishad et al. (Khoramishad et al., 2009).

Initially, the material parameters, $\left(\alpha, \beta, \varepsilon_{\mathrm{t}}\right)$ in Eq. (4), are adjusted to predict the experimental unaged load-life curves. The parameters $\alpha$ and $\beta$ govern the translation and the rotation of the load-life curve, whereas $\varepsilon_{\mathrm{t}}$ influences both the translation and the rotation of the load-life curve. For the unaged DB joint, the parameters were adjusted to fix the translation and the rotation and a good fit was obtained for $\left(\alpha, \beta, \varepsilon_{t}\right)=(1.0,2,0.0275)$. Using the unaged fatigue parameters and the estimated moisture concentrations, a coupled moisture-stress analysis was used to predict the aged load-life curve. The comparison between the predicted unaged/aged (360 days) load-life curves and the experimental test data are shown in Figure 13. The horizontal shift towards the load-axis shows that the moisture effect reduces the fatigue life for any given load level. The von Mises stress and the fatigue damage (SDEG) distributions obtained for the fatigue model are shown in Figure 14 for the DB at different fatigue stages $\left(\left(\mathrm{N} / \mathrm{N}_{\mathrm{f}} \approx 0.01, \mathrm{~N} / \mathrm{N}_{\mathrm{f}} \approx 0.9\right.\right.$ and $\left.\mathrm{N} / \mathrm{N}_{\mathrm{f}} \approx 1.0\right)$ when the fatigue maximum load was $\approx 2.6 \mathrm{kN}$. The damage initiation was near the fillet region. The maximum von Mises stress observed in the laminate was $\approx 295 \mathrm{MPa}$ (near the yield stress of Al 2024-T3) and no excessive plastic yielding was seen. Further, as the bending moment at the crack tip increased with the crack 
1 length, the crack propagation was accelerated. Nearly $90 \%$ of the fatigue life was spent creating a crack length that was half of the overlap length of the quarter-model (see Figure 14 when $\mathrm{N} / \mathrm{N}_{\mathrm{f}} \approx 0.9$ ).

As with the DB joint, the parameters were adjusted to fix the translation and the rotation of the S-N curves for the RSLJ and FSLJ. A good fit was obtained for $\left(\alpha, \beta, \varepsilon_{t}\right)=(0.1,2$, 0.0275). The authors speculate that the variation of the $\alpha$ value $(\alpha=1.0$ for the DB and $\alpha=0.1$ for the FSLJ/RSLJ) in the FSLJ/RSLJ was due to the initial curvature involved in the joints (which can induce gripping stresses when tested as FSLJ or RSLJ) and the cutting of the artificial groove after the joints were manufactured (which can redistribute any residual stresses present). Using the unaged fatigue parameters and the estimated moisture concentrations, a coupled moisture-stress analysis was then used to predict the aged load-life curve. The comparison between the predicted unaged/aged (360 and 720 days) load-life curves and the experimental test data are shown in Figures 15 and 16 for the FSLJ and the RSLJ, respectively. The horizontal shift towards the load-axis shows that the moisture effect reduces the fatigue life for any given load level.

The von Mises stress and the fatigue damage (SDEG) distributions obtained for the fatigue model are shown in Figure 17 for the FSLJ at different fatigue stages $\left(\left(\mathrm{N} / \mathrm{N}_{\mathrm{f}} \approx 0.01, \mathrm{~N} / \mathrm{N}_{\mathrm{f}}\right.\right.$ $\approx 0.9$ and $\mathrm{N} / \mathrm{N}_{\mathrm{f}} \approx 1.0$ ) when the fatigue maximum load was $\approx 5.4 \mathrm{kN}$. The damage initiation was near the tip of the artificial groove. The maximum von Mises stress observed in the laminate was $\approx 215 \mathrm{MPa}$ (less than the yield stress of Al 2024-T3). Initially, no damage was found in the fillet region (at the free-end of the stringer). However, after a certain crack length from the tip of the artificial groove, damage was seen at the fillet region (see Figure 17 when $\mathrm{N} / \mathrm{N}_{\mathrm{f}} \approx 0.9$ ). This pattern was in good correlation with the experimental observations. 
1 In this work, the adverse effect of a moist environment on the static and fatigue response of an adhesively bonded laminate (2024-T3/FM73 laminate and 2024-T3 stringer) joints were experimentally and numerically investigated. The joints tested were exposed to de-ionised water at $50^{\circ} \mathrm{C}$ for up to two years. Laboratory tests were conducted on unaged and aged joints to experimentally measure the reduction in the joint static strengths and the fatigue life. A cohesive-zone approach was used for the critical adhesive bondline in a coupled stressdiffusion analysis to model the static and fatigue failures. A strain-based fatigue damage model was used for the adhesive material in the fatigue failure analysis. The following conclusions are drawn:

(a) A considerable reduction (up to 15\%) in the static strengths of the joints (DB, 
Abdel Wahab, M.M., Ashcroft, I.A., Crocombe, A.D., Hughes, D.J. and Shaw, S.J. (2001). The Effect of Environment on the Fatigue of Bonded Composite Joints. Part 2: Fatigue Threshold Prediction, Composites: Part A, 32: 59-69.

Adams, R.D. and Comyn, J. (1997). Structural Adhesive Joints in Engineering, Springer, 2nd Edition (ISBN: 0412709201).

Alfano, G. (2006). On the Influence of the Shape of the Interface Law on the Application of Cohesive-Zone Models, Composites Science and Technology, 66: 723-730.

Armstrong, K.B. (1997). Long-term Durability in Water of Aluminium Alloy Adhesive Joints Bonded with Epoxy Adhesives, International Journal of Adhesion and Adhesives, 17: 89-105.

Barrenblatt, G.I. (1962). The Mathematical Theory of Equilibrium Cracks in Brittle Fracture, Advances in Applied Mechanics, 7: 55-129.

Benzeggagh, M.L. and Kenane, M. (1996). Measurement of Mixed-mode Delamination Fracture Toughness of Unidirectional Glass/Epoxy Composites with Mixed-mode Bending Apparatus, Composite Science and Technology, 56, p 439-449.

Bowditch, M.R. (1996). The Durability of Adhesive Joints in the Presence of Water, International Journal of Adhesion and Adhesives, 16: 73-79.

Brewis, D.M., Comyn, J., Raval, A.K. and Kinloch, A.J. (1990). The Effect of Humidity on the Durability of Aluminium-Epoxide Joints, International Journal of Adhesion and Adhesives, 10: 247-253.

Crocombe, A.D. (1997). Durability Modelling Concepts and Tools for the Cohesive Environmental Degradation of Bonded Structures, International Journal of Adhesion and Adhesives, 17: 229-38.

Davis, S.J. and Watts, J.F. (1996). Interfacial Chemistry of Adhesive Joint Failure: An Investigation by Small Area XPS, Imaging XPS and TOF-SIMS, Journal of Material Chemistry, 6: 479-493.

de Nèvea, B. and Shanahan, M.E.R. (1992). Effects of Humidity on an Epoxy Adhesive, International Journal of Adhesion and Adhesives, 12: 191-196. 
Dickie RA, Haack LP, Jethwa JK, Kinloch AJ and Watts JF (1998). The Fatigue and Durability Behaviour of Automotive Adhesives, Part II: Failure Mechanisms, Journal of Adhesion, 66: 1-37.

Diehl, T. (2008). On using a Penalty-Based Cohesive-Zone Finite Element Approach, Part I: Elastic Solution Benchmarks, International Journal of Adhesion and Adhesives, 28: $237-255$.

Dugdale, D.S. (1960). Yielding of Steel Sheets Containing Slits, Journal of the Mechanics and Physics of Solids, 8: 100-104.

Fernando, M., Harjoprayitno, W.W. and Kinloch, A.J. (1996). A Fracture Mechanics Study of the Influence of Moisture on the Fatigue Behaviour of Adhesively Bonded Aluminium-Alloy Joints, International Journal of Adhesion and Adhesives, 16: 113-119.

Gerald Doyle and Richard A. Pethrick (2009). Environmental Effects on the Ageing of Epoxy Adhesive Joints, International Journal of Adhesion and Adhesives, 29: 77-90.

Hua, Y., Crocombe, A.D., Wahab, M.A. and Ashcroft, I.A. (2008). Continuum Damage Modelling of Environmental Degradation in Joints Bonded with EA9321 Epoxy Adhesive, International Journal of Adhesion and Adhesives, 28: 302-313.

Ingram, C. and Ramani, K. (1997). The Effect of Sodium Hydroxide Anodization on the Durability of Poly(etherketonetherketoneketone) Adhesive Bonding of Titanium, International Journal of Adhesion and Adhesives, 17: 39-45.

Katnam, K.B., Crocombe, A.D., Khoramishad, H. and Ashcroft, I.A. (2009). The Static Failure of Adhesively Bonded Metal Laminate Structures: A Cohesive Zone Approach, Journal of Adhesion Science and Technology (accepted).

Katnam, K.B., Sargent, J.P., Crocombe, A.D., Khoramishad, H. and Ashcroft, I.A. (2009). Characterisation of Moisture-Dependent Cohesive Zone Properties for Adhesively Bonded Joints, Engineering Fracture Mechanics, 77: 3105-3119.

Khoramishad, H., Crocombe, A.D., Katnam, K.B. and Ashcroft, I.A. (2009). Predicting Fatigue Damage in Adhesively Bonded Joints using a Cohesive Zone Model, International Journal of Fatigue, 32:1146-1158.

Kinloch, A.J. (1983). Durability of Structural Adhesives, Elsevier Applied Science, Amsterdam, 30-31 (ISBN 0853342148). 
Kinloch, A.J. (1995). Adhesion and Adhesives, Chapman \& Hall, London (ISBN 041227440X).

Liljedahl, C.D.M., Crocombe, A.D., Wahab, M.M.A. and Ashcroft, I.A. (2006). Modelling the Environmental Degradation of the Interface in Adhesively Bonded Joints using a Cohesive Zone Approach, Journal of Adhesion, 82: 1061-1089.

Liljedahl, C.D.M. (2006). Modelling the Interfacial Degradation in Adhesively Bonded Joints, PhD Thesis, University of Surrey, Guildford, UK.

Loh, W.K., Crocombe, A.D., Abdel Wahab, M.M. and Ashcroft, I.A. (2005). Modelling Anomalous Moisture Uptake, Swelling and Thermal Characteristics of a Rubber Toughened Epoxy Adhesive, International Journal of Adhesion and Adhesives, 25: 1-12.

Minford, J.D. (1985). Comparative Aluminium Joint Evaluations in Varying Saltwater Exposure Conditions, Journal of Adhesion, 18: 19-24.

Ning Sua, Mackie, R.I. and Harveya, W.J. (1992). The Effects of Ageing and Environment on the Fatigue Life of Adhesive Joints, International Journal of Adhesion and Adhesives, 12: 85-93.

Rider, A.N., Brack, N., Andres, S. and Pigram, P.J. (2204). The Influence of Hydroxyl Group Concentration on Epoxy-Aluminium Bond Durability, Journal of Adhesion Science and Technology, 18: 1123-1152.

Rider, A.N. and Arnott, D.R. (1996). Durability of Bonds Formed Between Epoxy Adhesive and Aluminium Alloy Treated with Phosphonate Inhibitors, Surface and Interface Analysis, 24: 583-590.

Rodriguez, F. (1996). Principle of Polymer Systems, Taylor \& Francis, London (ISBN 1560323256).

Sargent, J.P. (2005). Durability Studies for Aerospace Applications using Peel and Wedge Tests, International Journal of Adhesion and Adhesives, 25: 247-56.

Takafumi Kawaguchi and Raymond A. Pearson (2004). The Moisture Effect on the Fatigue Crack Growth of Glass Particle and Fibre Reinforced Epoxies with Strong and Weak Bonding Conditions: Part 1. Macroscopic Fatigue Crack Propagation Behaviour, Composites Science and Technology, 64: 1981-1989. 
Turner, R.H., Segall, I., Boerio, F.J. and Davis, G.D. (1997). Effect of PlasmaPolymerized Primers on the Durability of Aluminum/Epoxy Adhesive Bonds, Journal of Adhesion, 62: 1-21.

Wolfe, K.L., Dillard, J.G., Harp, S.R. and Grant, J.W. (1997). Plasma-Sprayed Aluminum and Titanium Adherends: II. Durability Studies for Wedge Specimens Bonded with Polyimide Adhesive, Journal of Adhesion, 60: 141-52.

Yang, Q.D., Thouless, M.D. and Ward, S.M. (2001). Elastic-Plastic Mode-II Fracture of Adhesive Joints, International Journal of Solids and Structures, 38: 3251-3262.

(1)


TABLES:

2

3

4 Table 1: Material details of Al 2024-T3

\begin{tabular}{llllll}
\hline Al 2024-T3 & $\begin{array}{l}\text { Young's modulus } \\
(\mathrm{MPa})\end{array}$ & Poisson's ratio & $\begin{array}{l}\text { Yield stress } \\
(\mathrm{MPa})\end{array}$ & $\begin{array}{l}\text { Ultimate stress } \\
(\mathrm{MPa})\end{array}$ & $\begin{array}{l}\text { Elongation } \\
(\%)\end{array}$ \\
\hline 70,000 & 0.33 & 290 & 450 & 16
\end{tabular}

5

6

7

$8 \quad$ Table 2: Material details of FM73

\begin{tabular}{lllll}
\hline FM73 & $\begin{array}{l}\text { Young's modulus } \\
(\mathrm{MPa})\end{array}$ & $\begin{array}{l}\text { Poisson's } \\
\text { ratio }\end{array}$ & $\begin{array}{l}\text { Tripping traction } \\
\text { Mode-I/Mode-II }(\mathrm{MPa})\end{array}$ & $\begin{array}{l}\text { Fracture energy Mode- } \\
\text { I/Model-II }\left(\mathrm{Nmm}^{-1}\right)\end{array}$ \\
\hline Dry & 2000 & 0.4 & $65 / 38$ & $2.0 / 4.0$ \\
\hline Saturated & 1680 & 0.4 & $54.6 / 31.9$ & $1.68 / 3.36$
\end{tabular}

9

10

11

12

13

14

15

16 


\section{FIGURES:}

2

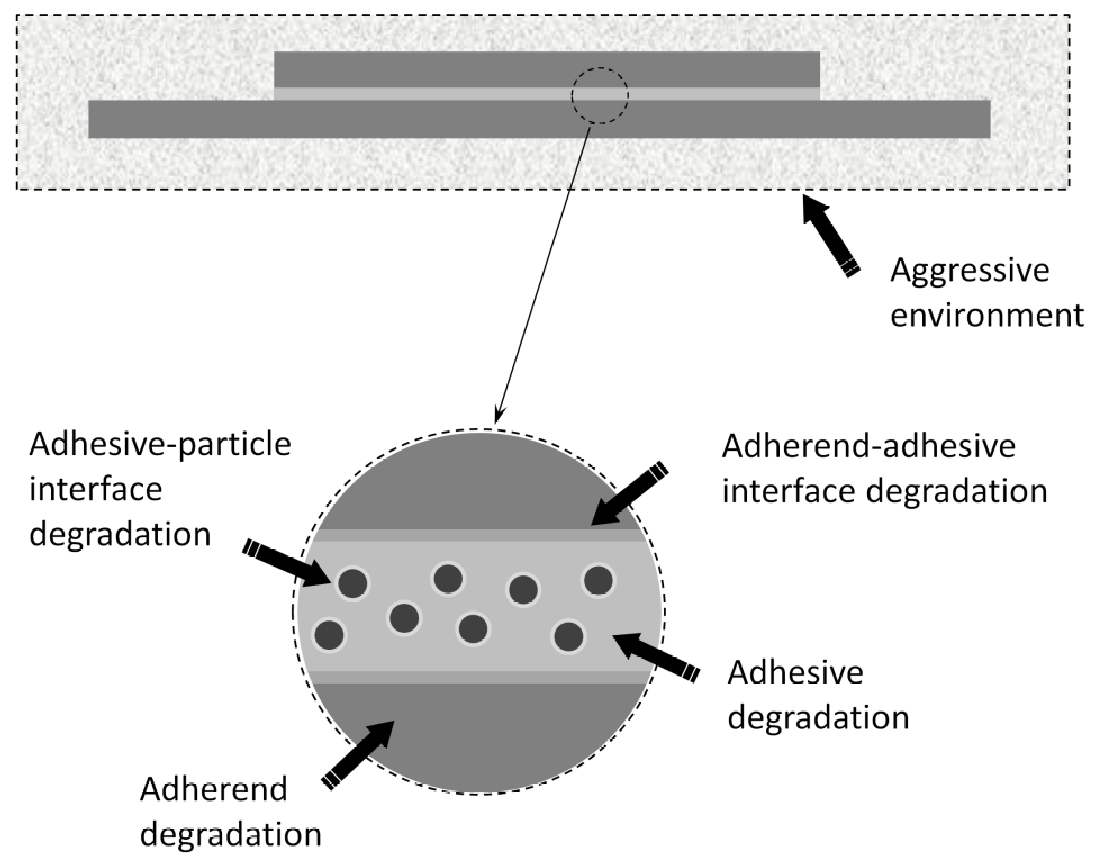

8

Figure 1: The effect of moist environment on adhesively bonded joint.

9 


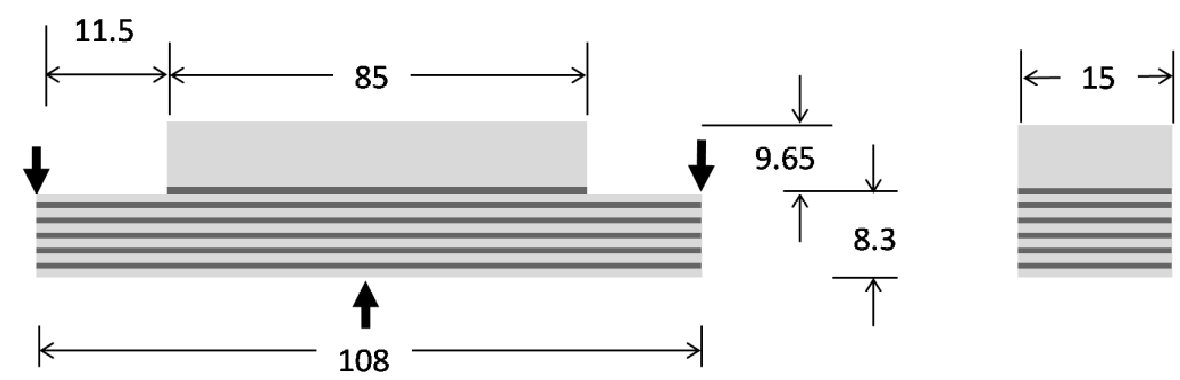

(a) Doubler in bending

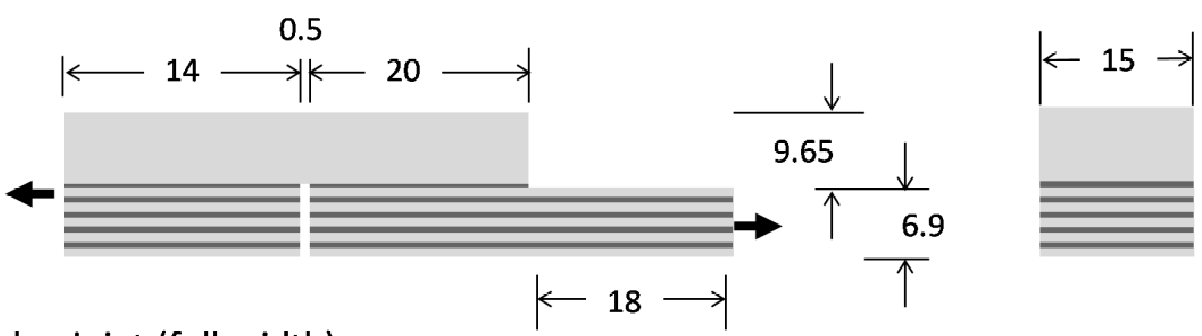

(b) Single lap joint (full-width)

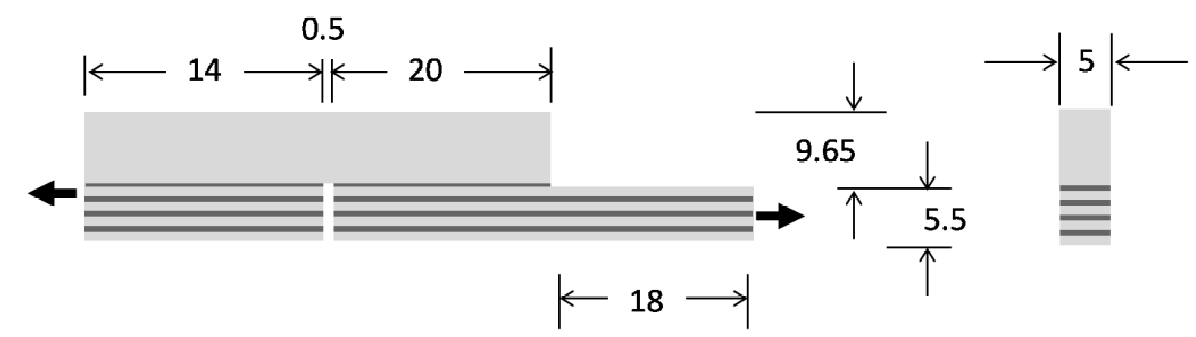

(c) Single lap joint (reduced-width)

Adhesive FM73

Aluminium 2024-T3

Figure 2: The dimensional details of the joint configurations.

5

6

7 


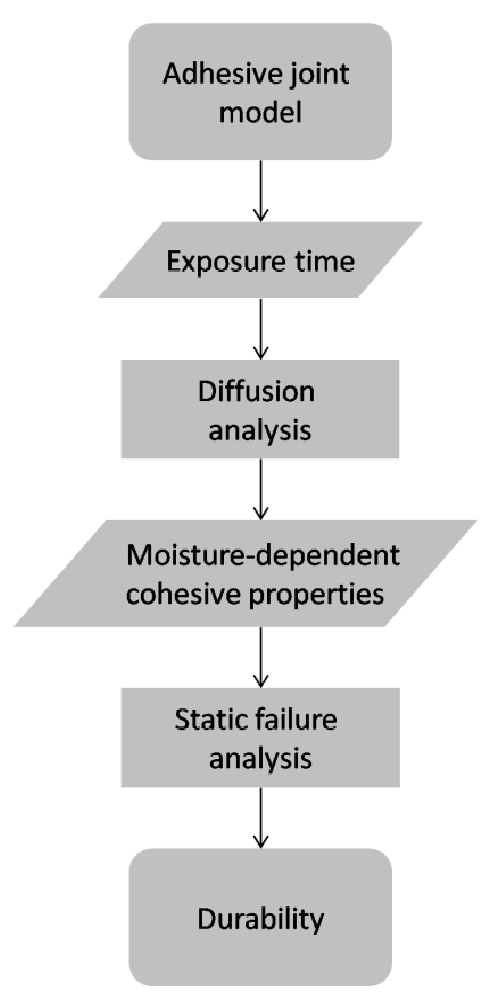

2

3 


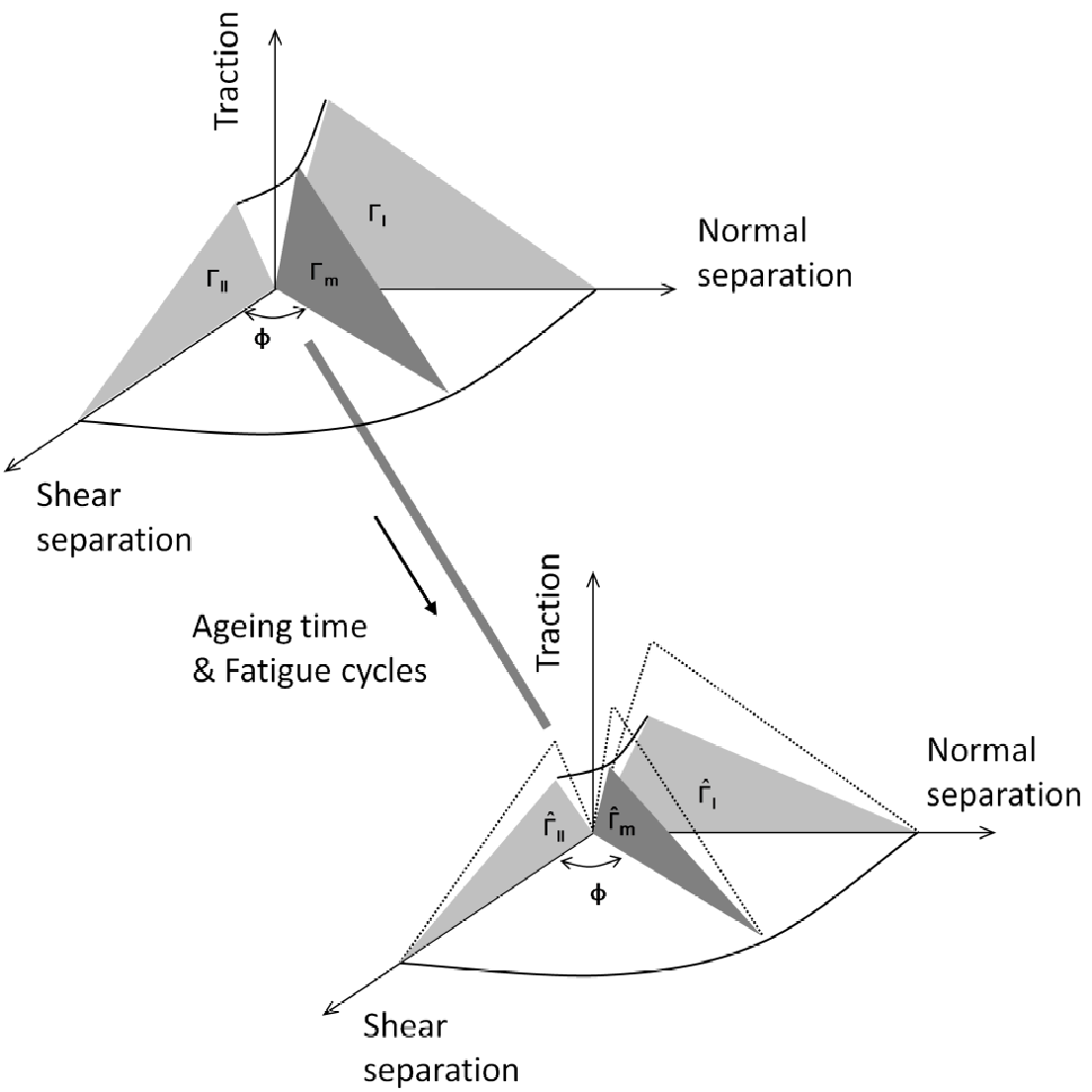

(a)

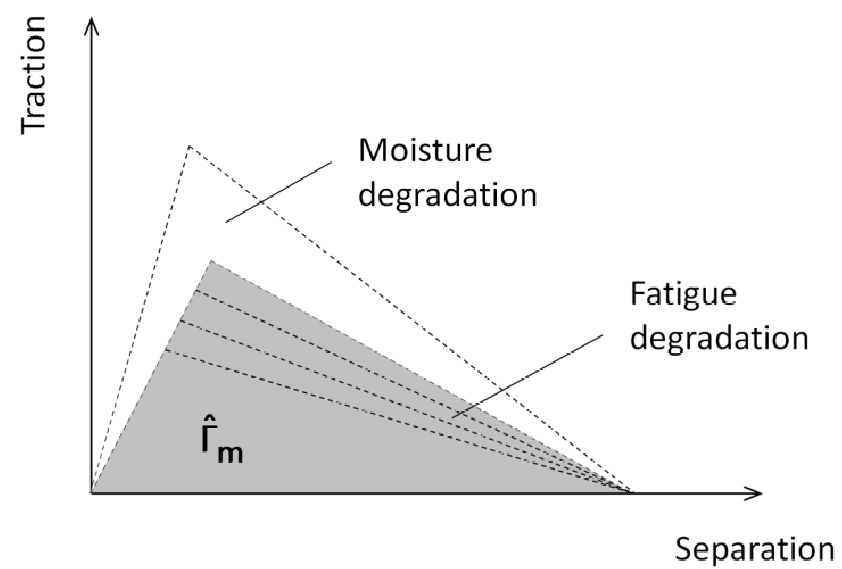

(b)

Figure 4: The degradation of the cohesive properties: (a) The cohesive responses (normal and shear) of adhesive bondline before and after exposure to moisture (ageing) and fatigue cycles and (b) the degradation of the mixed-mode traction-separation 6 response due to moisture and fatigue. 


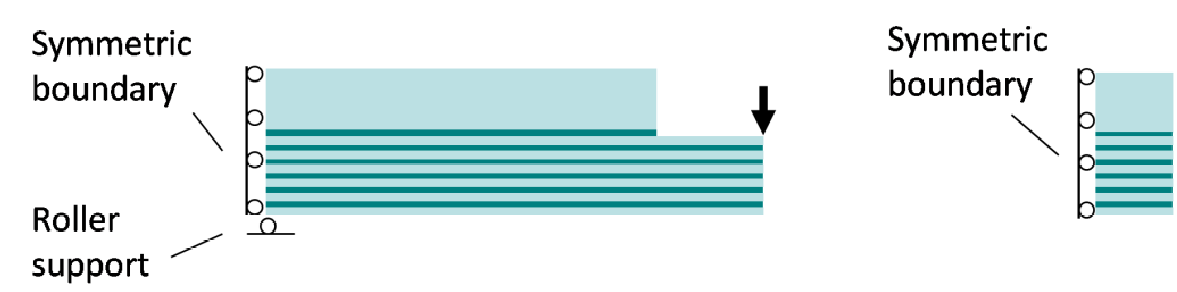

(a) Doubler in bending (quarter-model)

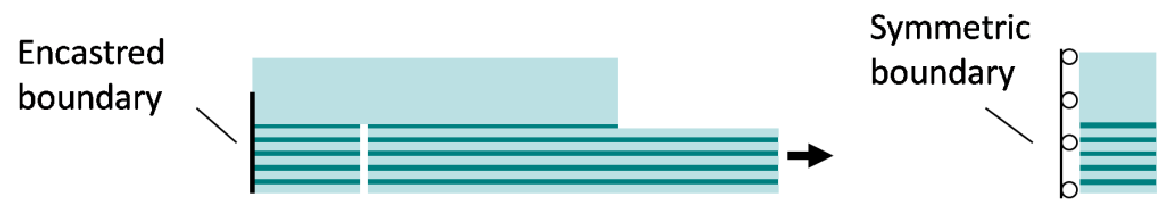

(b) Single lap joint (half-model)

Adhesive FM73 Aluminium 2024-T3

2 Figure 5: The boundary conditions in the FE models for the DB and the FSLJ/RSLJ.

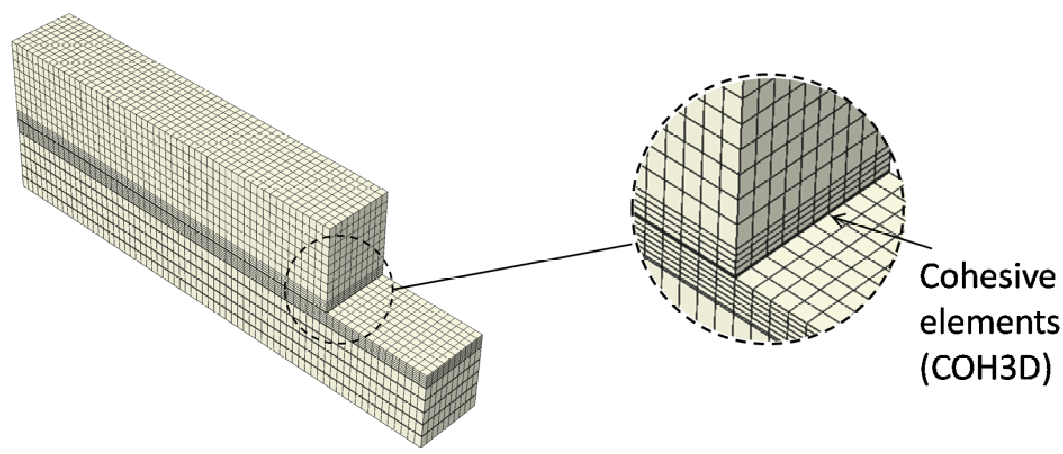

(a) Mesh details in DB (quarter-model)

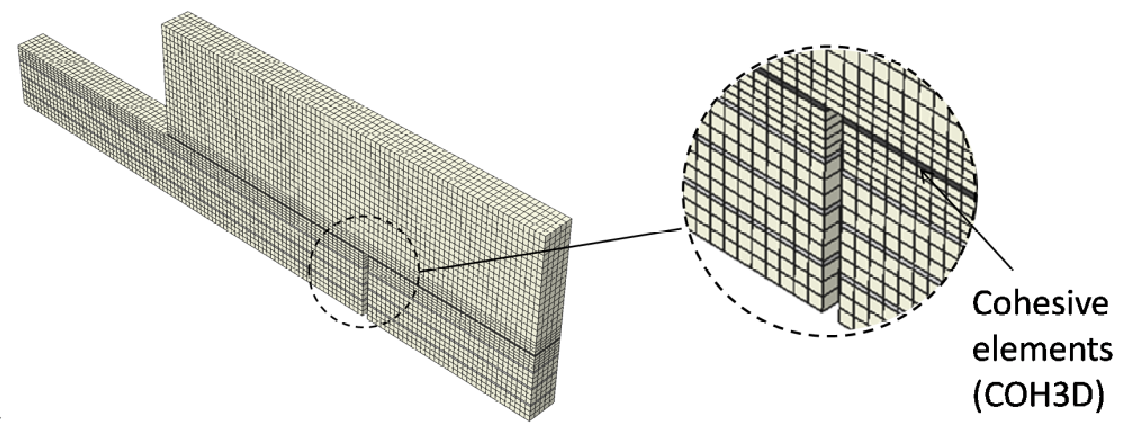

(b) Mesh details in RSLJ (quarter-model)

4 Figure 6: The finite element mesh used for the DB and the RSLJ (similar for the FSLJ). 


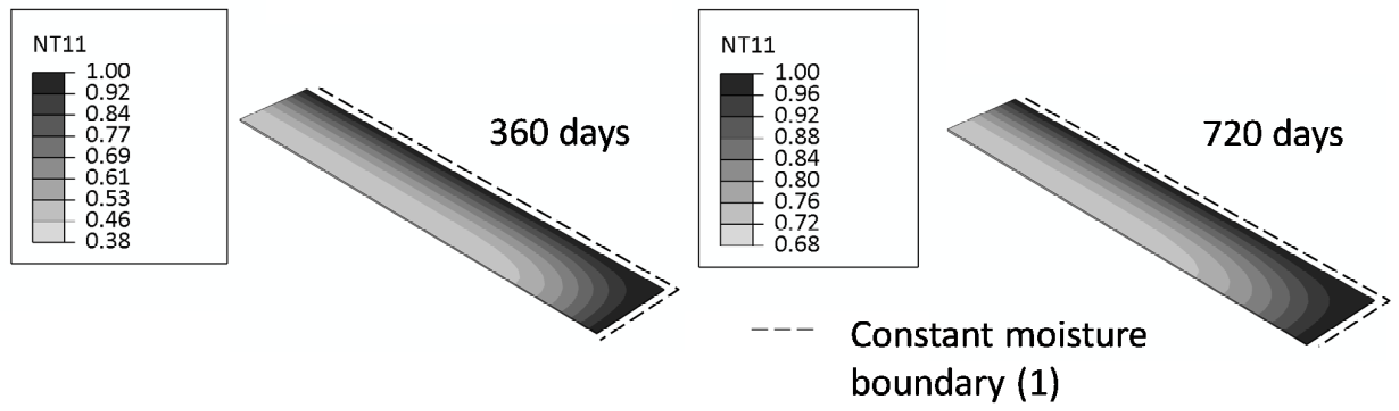

(a) Moisture diffusion in DB (quarter-model)
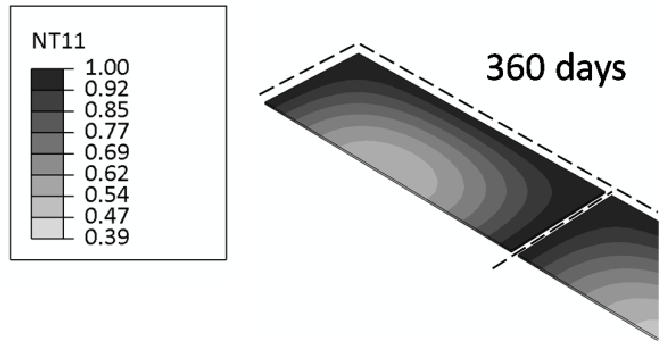

(b) Moisture diffusion in FSL (half-model)

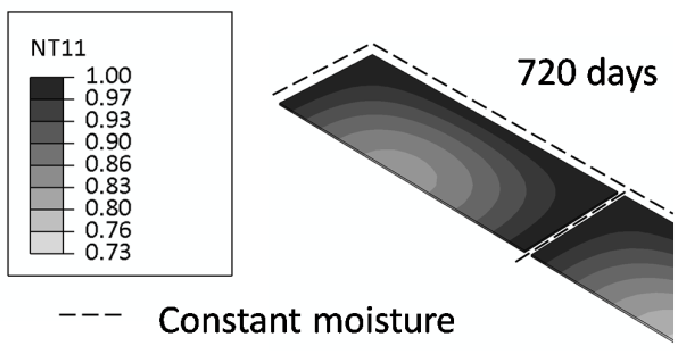
boundary (1)
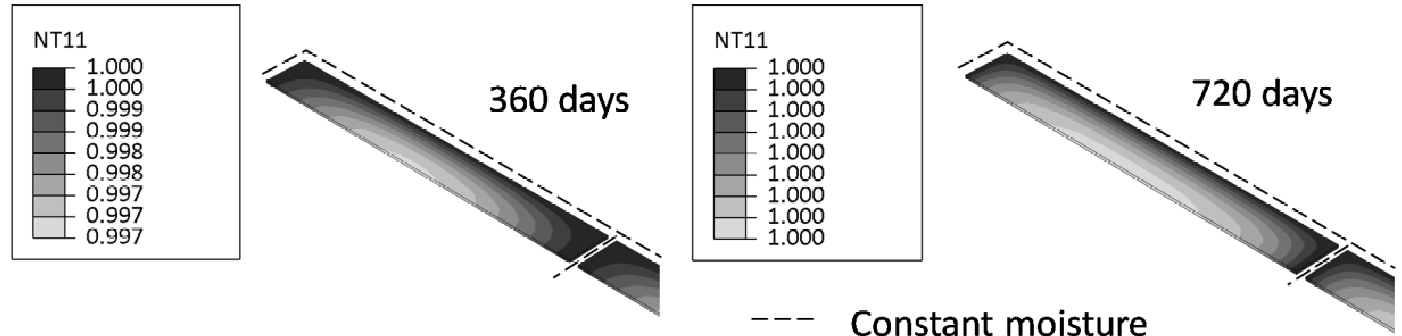

(c) Moisture diffusion in RSLJ (half-model) boundary (1)

Figure 7: The estimated moisture distributions after 360 and 720 days of exposure in the DB, the FSLJ, and the RSLJ.

6 


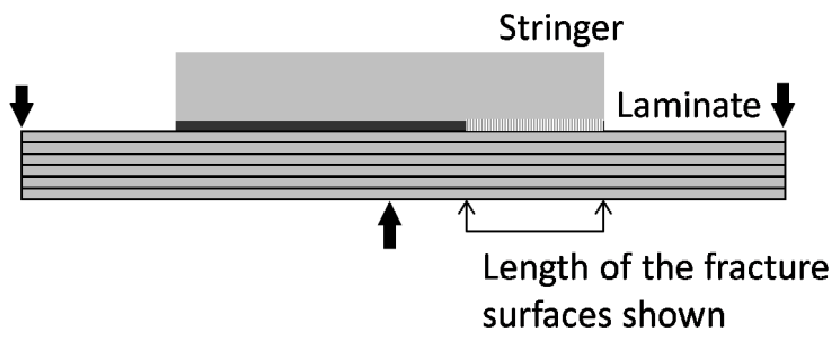

(a) Doubler in bending

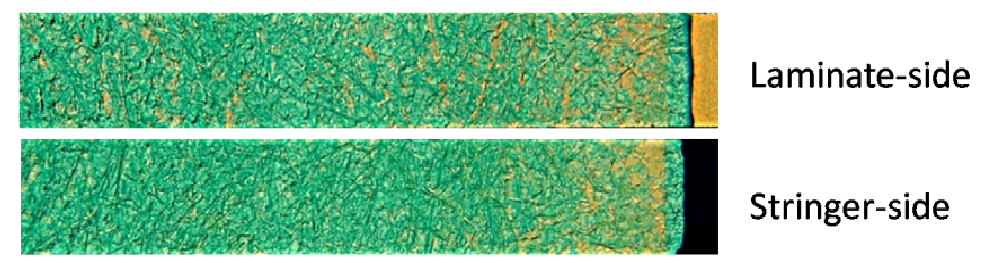

(b) Static failure surfaces: Unaged adhesive bondline

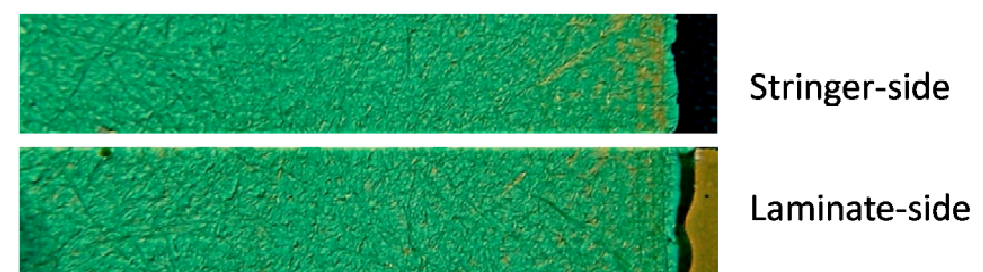

(c) Static failure surfaces: Aged adhesive bondline 


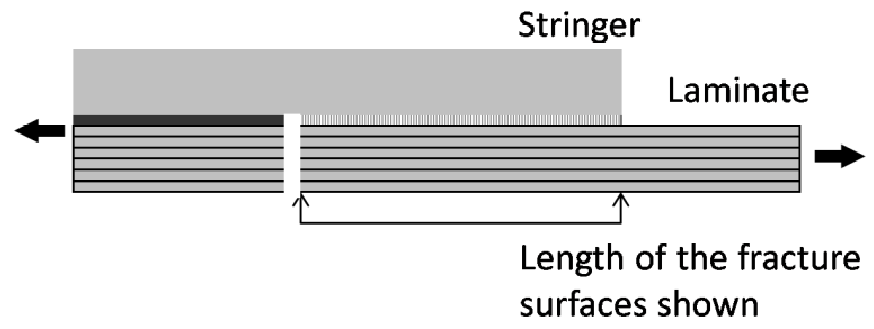

(a) Single lap joint (reduced-width)

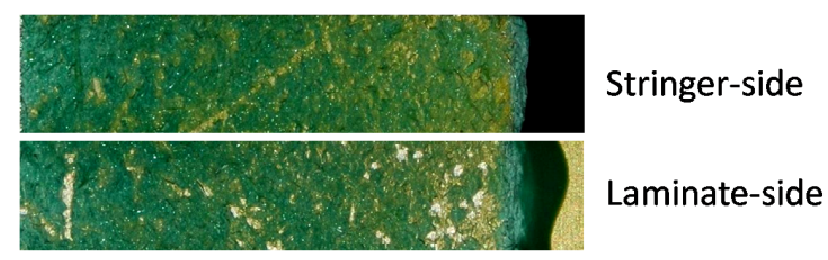

(b) Static failure surfaces: Unaged adhesive bondline

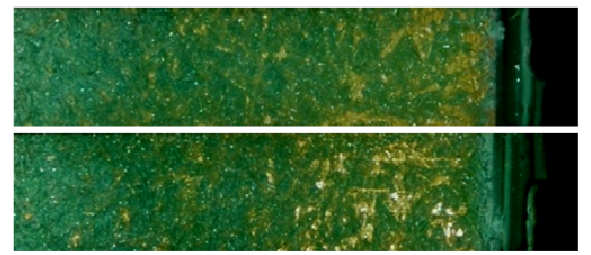

Stringer-side

Laminate-side

(c) Static failure surfaces: Aged adhesive bondline

6

Figure 9: Static failure surfaces from the unaged and the aged RSLJ.

8

9

10

11 


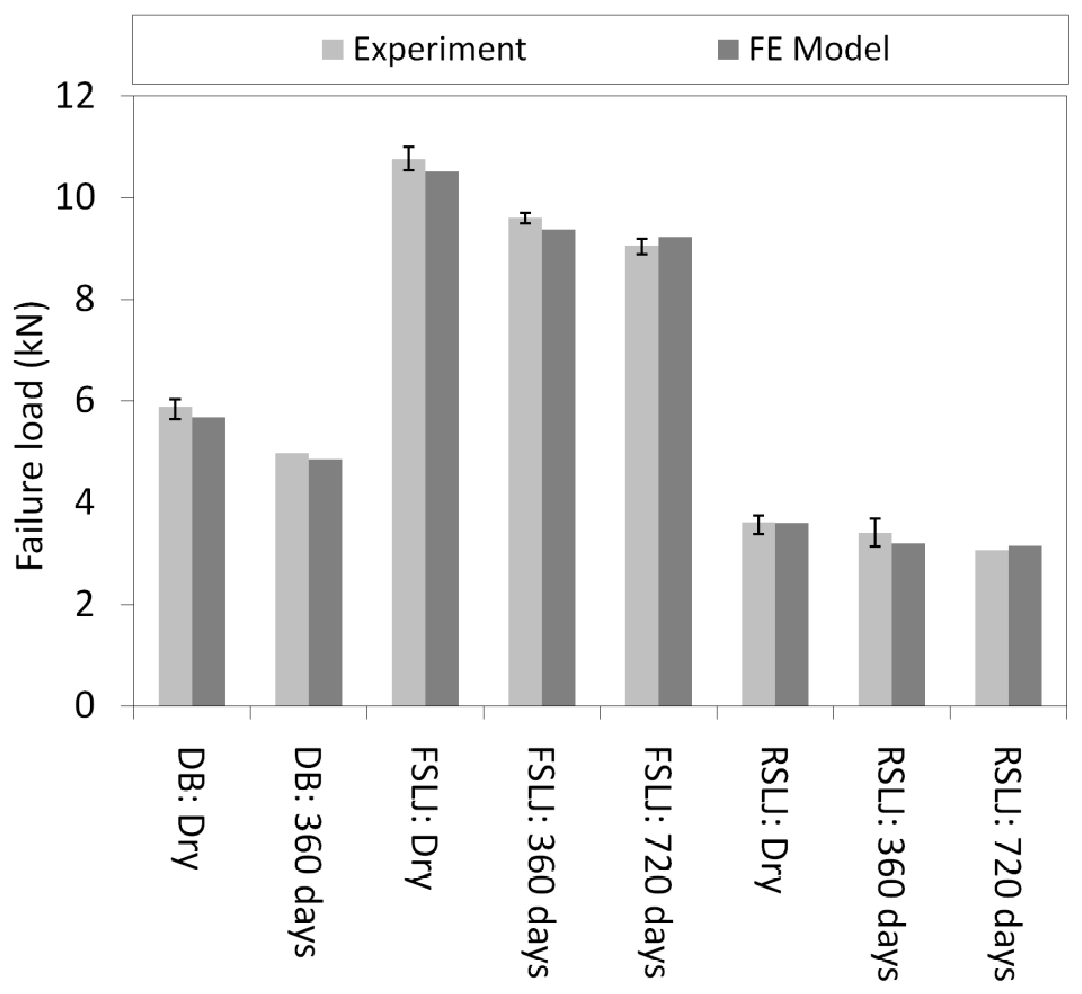

6

7 Figure 10: The comparison between the predicted static failure loads against the 8 experimental data for the DB, the FSLJ and the RSLJ for the unaged (dry) and the 9 aged (360 and 720 days) conditions. 


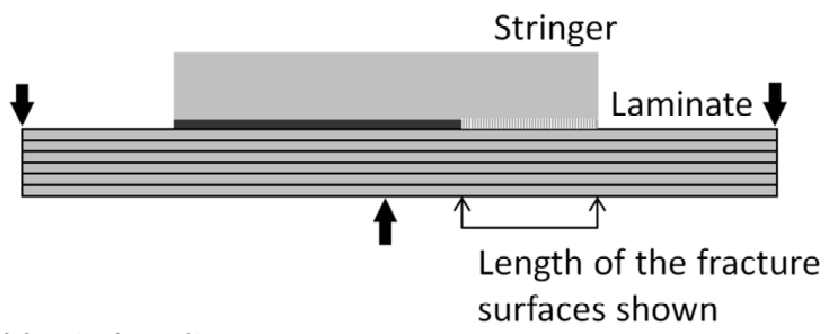

(a) Doubler in bending

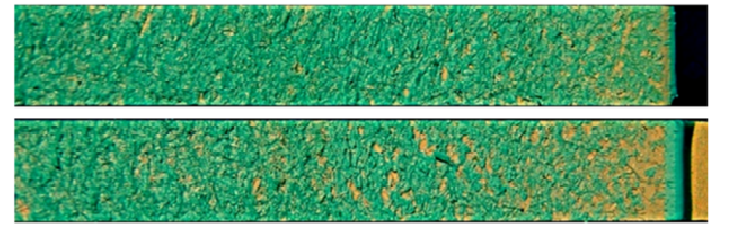

Stringer-side

Laminate-side

(b) Fatigue failure surfaces: Unaged adhesive bondline

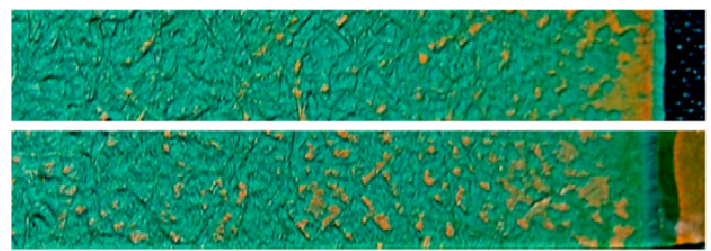

Stringer-side

Laminate-side

5

(c) Fatigue failure surfaces: Aged adhesive bondline

Figure 11: Fatigue failure surfaces from the unaged and the aged DB joints. 


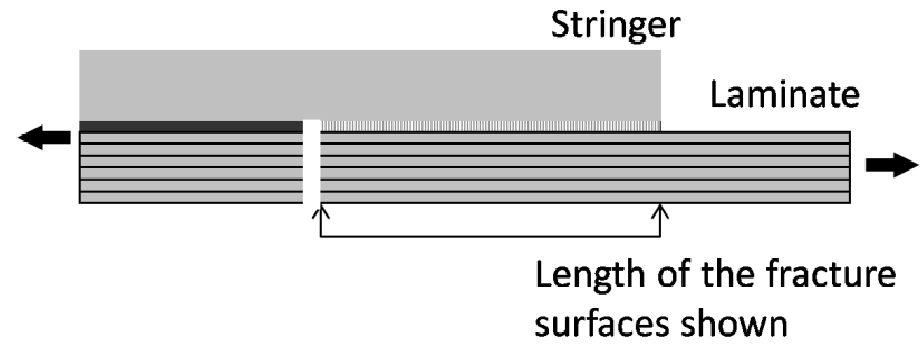

(a) Single lap joint (reduced-width)

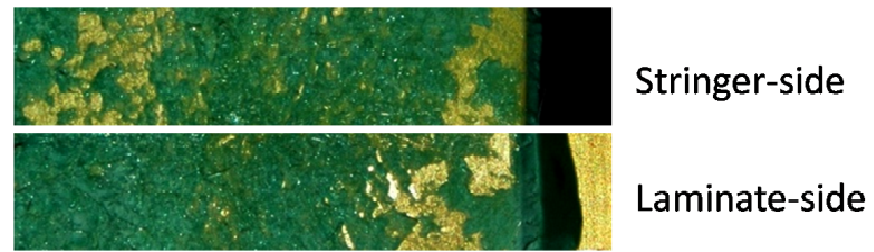

(b) Fatigue failure surfaces: Unaged adhesive bondline

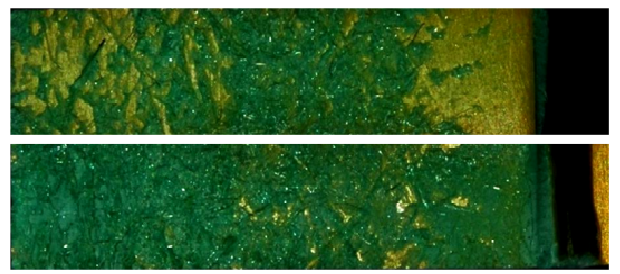

Stringer-side

Laminate-side

(c) Fatigue failure surfaces: Aged adhesive bondline 


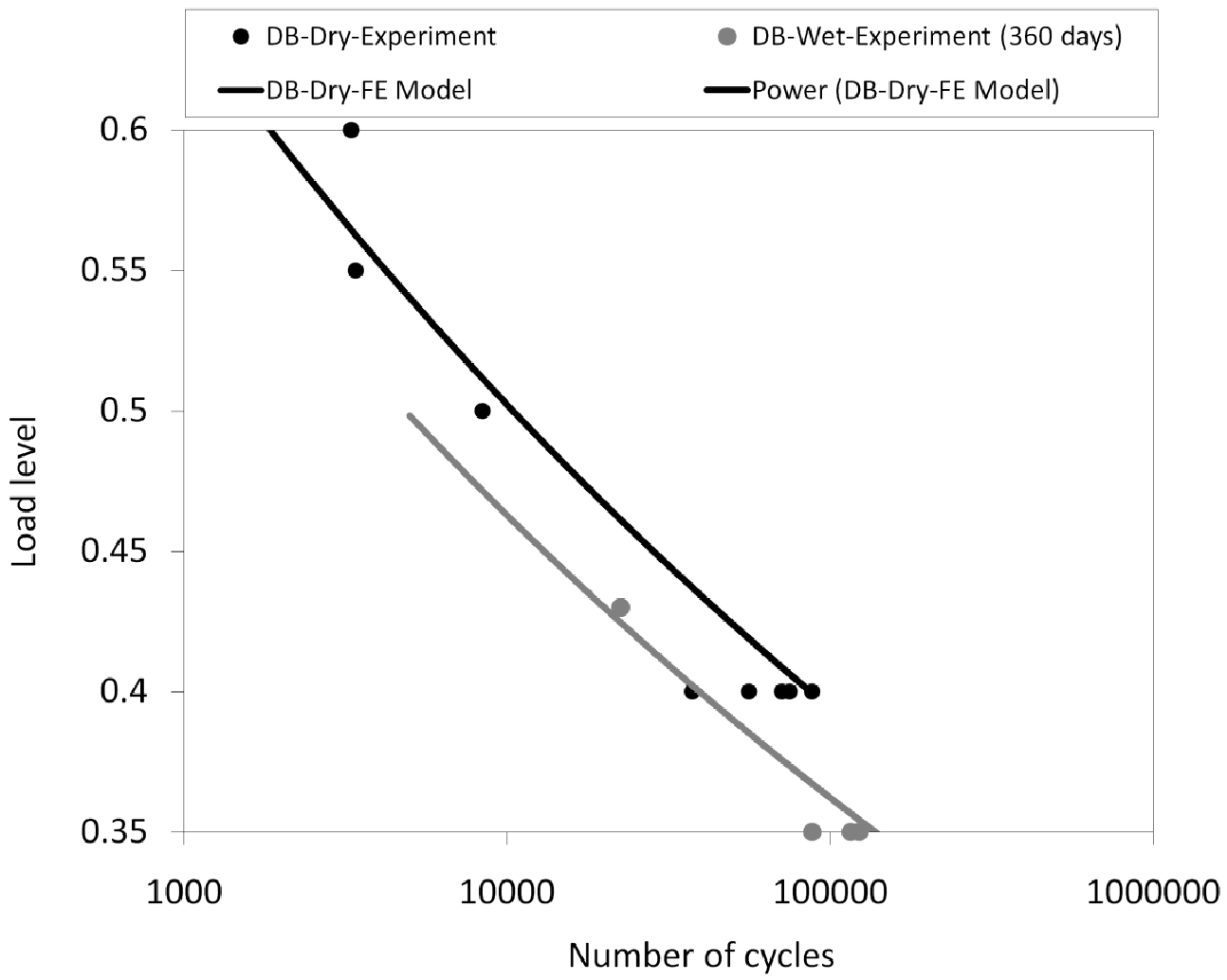

3

Figure 13: Comparison of the predicted unaged and aged (360 days) load-life curves 5 against the experimental test data for the DB.

6

7

8

9

10 

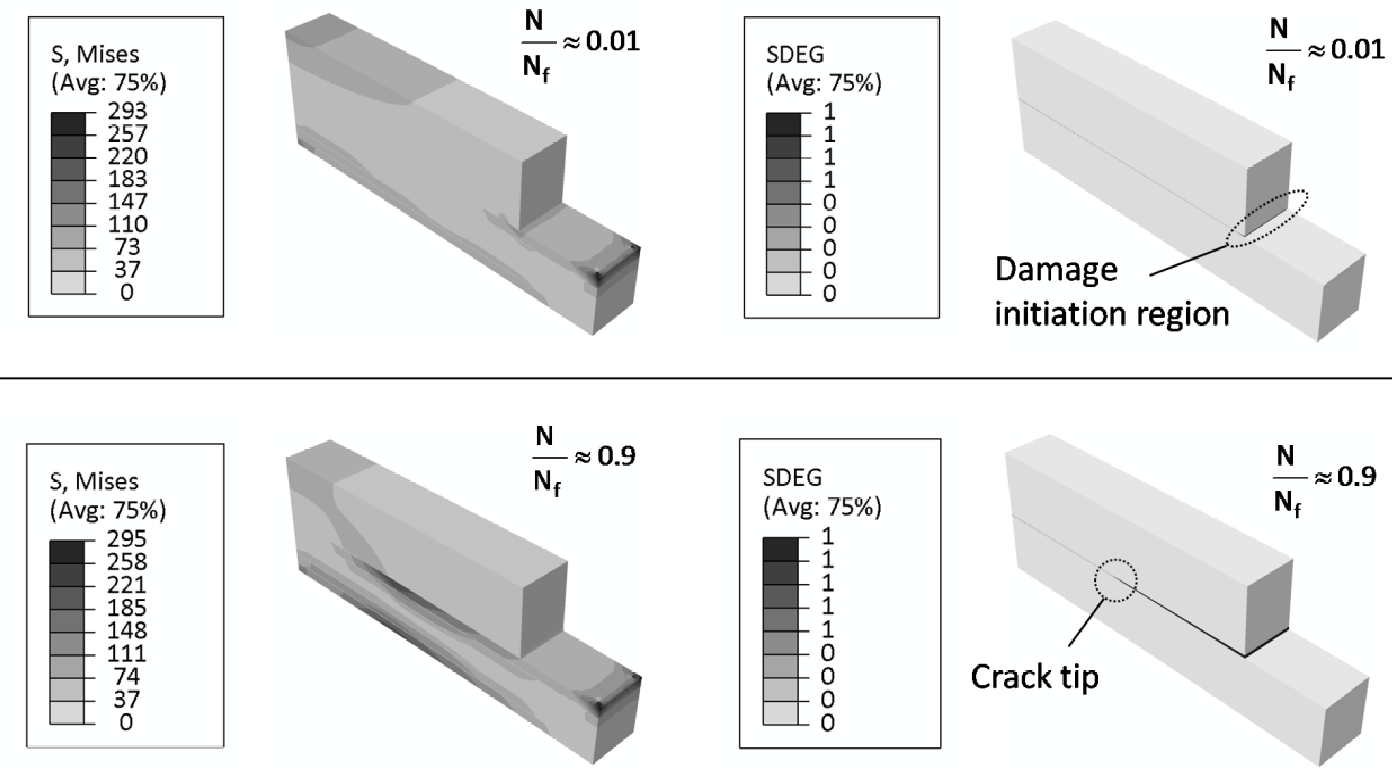

$$
\frac{N}{N_{f}} \approx 0.9
$$

Crack tip
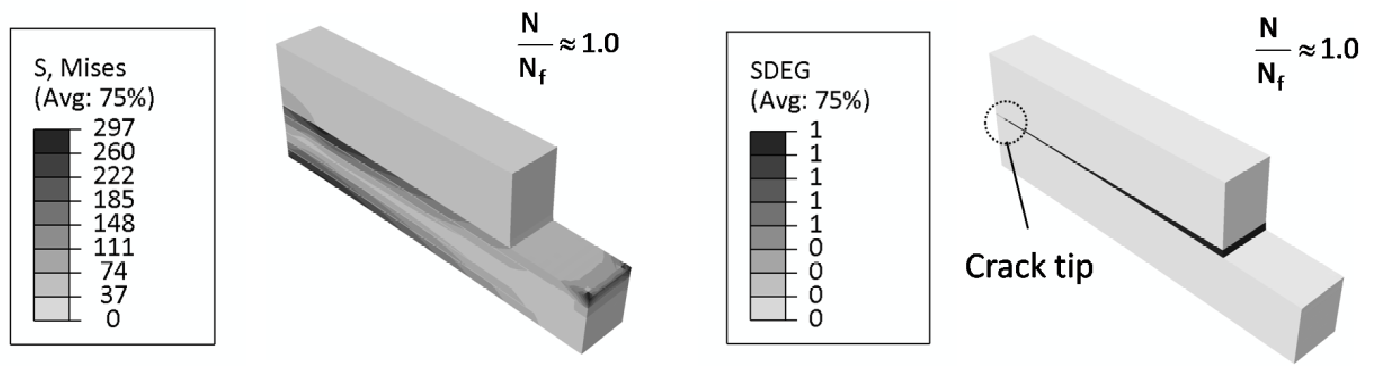

Figure 14: The von Mises stress and the damage variable (SDEG) distributions in the maximum load was $\approx 2.6 \mathrm{kN}$. 


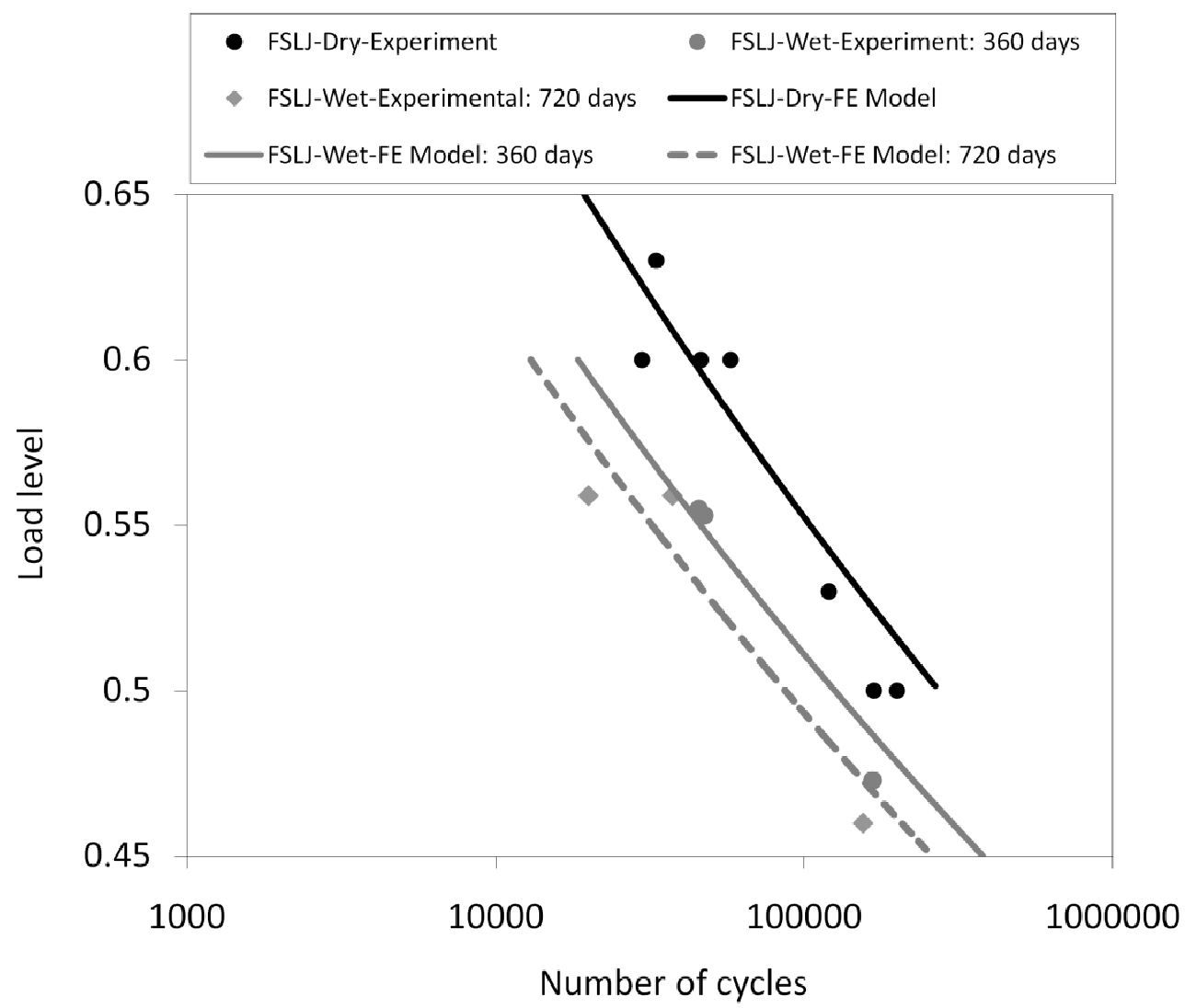

5

Figure 15: Comparison of the predicted unaged and aged (360 and 720 days) load-life 6 curves against the experimental test data for the FSLJ.

7

8

9

10

11

12 


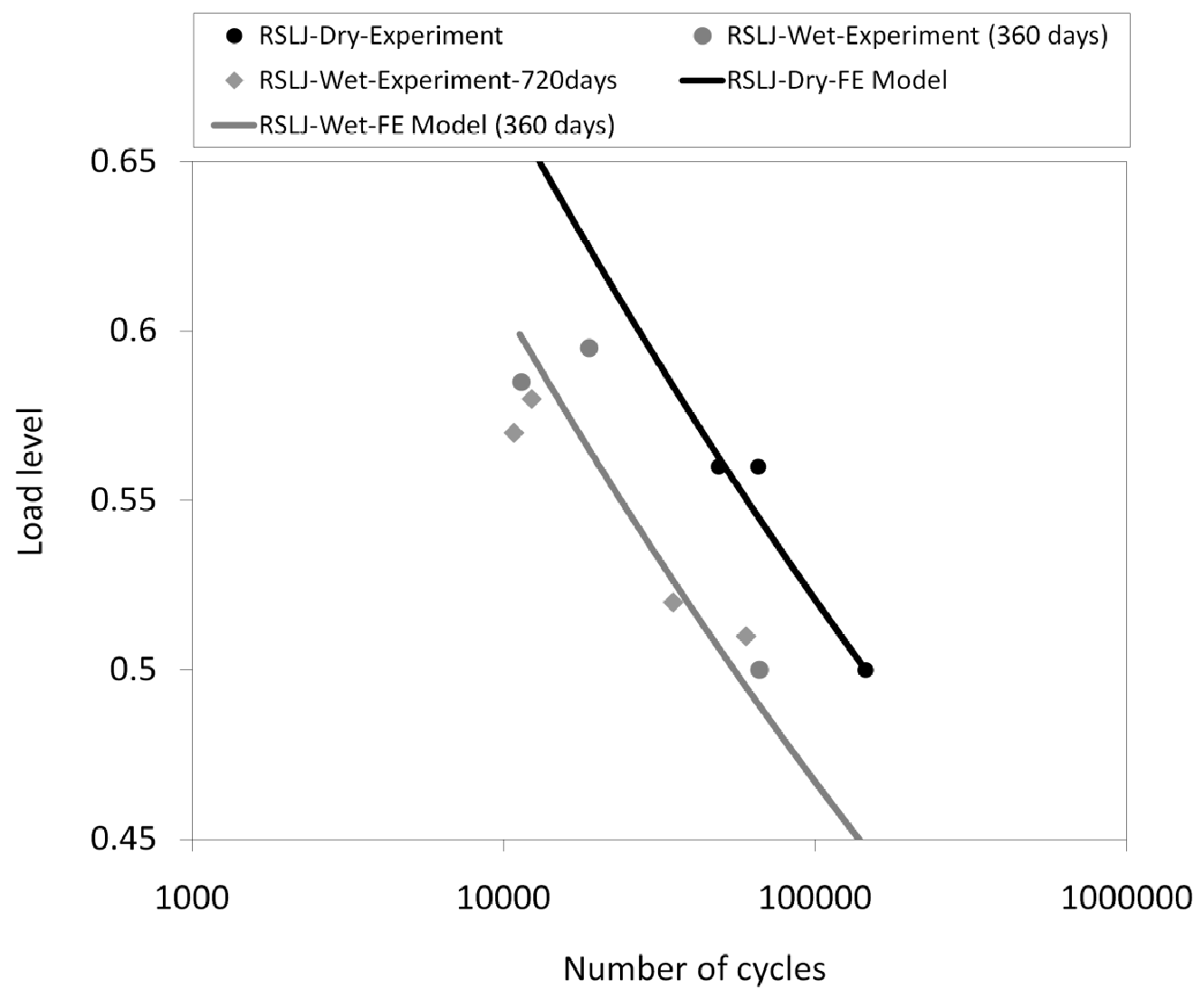

Figure 16: Comparison of the predicted unaged and aged (360 days) load-life curves against the experimental test data for the RSLJ.

6 

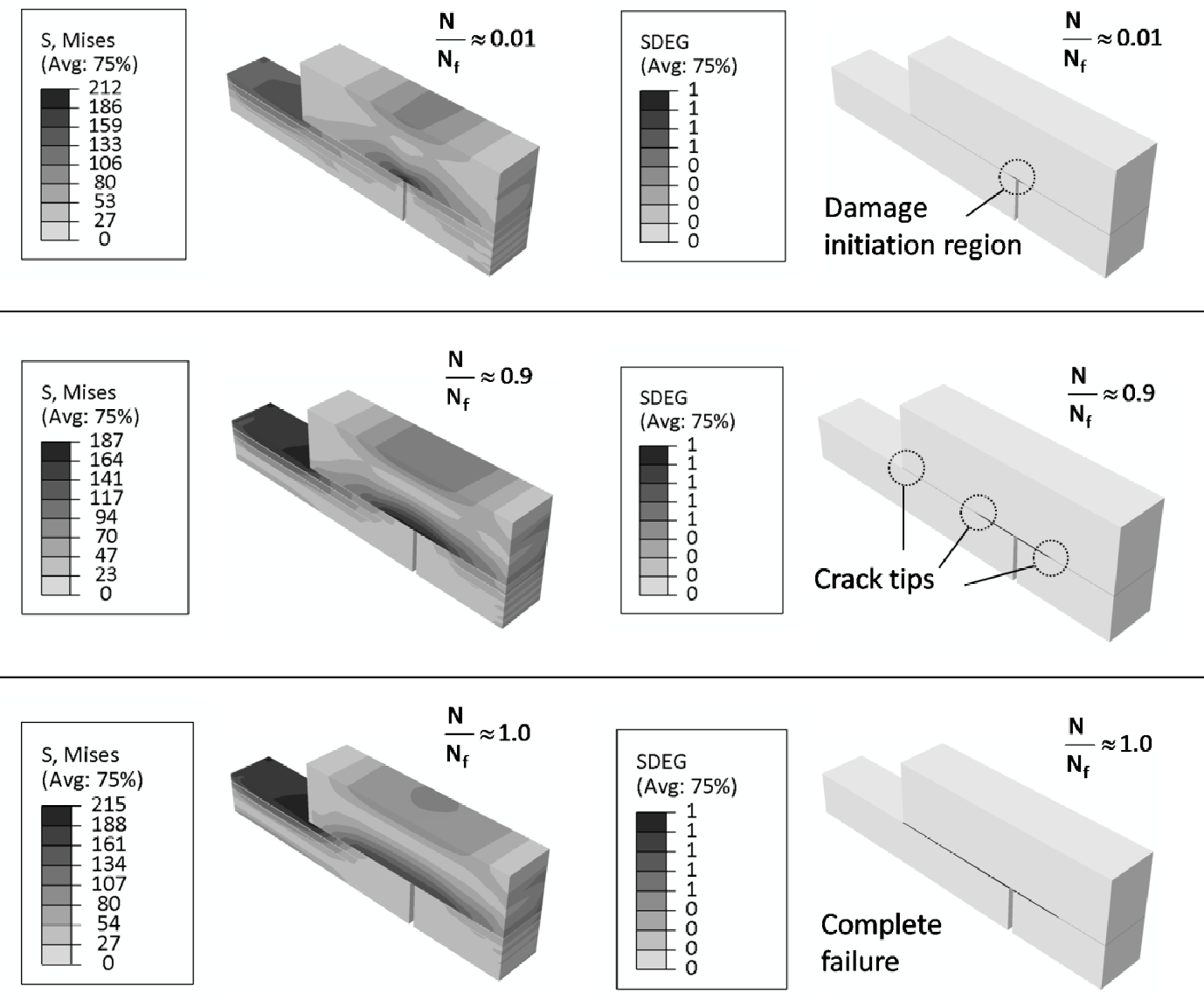

3

$4 \quad$ Figure 17: The von Mises stress and the damage variable (SDEG) distributions in the 5 FSLJ at different fatigue stages $\left(N / N_{f}=0.01, N / N_{f}=0.9\right.$ and $\left.N / N_{f}=1.0\right)$ when the fatigue 6 maximum load was $\approx 5.4 \mathrm{kN}$. 